Saudi Journal of Humanities and Social Sciences

Abbreviated Key Title: Saudi J Humanities Soc Sci

ISSN 2415-6256 (Print) | ISSN 2415-6248 (Online)

Scholars Middle East Publishers, Dubai, United Arab Emirates

Journal homepage: http://scholarsmepub.com/sihss/

Review Article

\title{
Language and Thought, Which one comes First? Thought with or without Language
}

\author{
Meisam Ziafar ${ }^{1}$, Ehsan Namaziandost ${ }^{2 *}$ \\ ${ }^{1}$ Assistant Professor, Department of English Language Teaching, Ahvaz Branch, Islamic Azad University, Ahvaz, Iran \\ ${ }^{2}$ Ph.D. Candidate in TEFL, Department of English, Faculty of Humanities, Shahrekord Branch, Islamic Azad University, Shahrekord, Iran
}

DOI: $10.36348 /$ sjhss.2019.v04i12.005 $\quad$ | Received: 08.11.2019| Accepted: 15.11 .2019 | Published: 25.12 .2019

*Corresponding author: Ehsan Namaziandost

\section{Abstract}

Claim has always been made that thought and language are inseparatable phenomena. Accordingly, major debate has revolved around the dependence or interdependence of language and thought. Based on linguistic relativity hypothesis, our perception of reality depends on the language we speak. The counterclaim has also been made that languages are not so much different and this makes us skeptical of the idea that their speakers have different thoughts. Some hold the belief that language may not serve a proper medium for thought, mentioning extralinguistic drawbacks such as ambiguity, deixis, and co-reference. All in all, it seems rational to maintain that thought and language have compromised to coexist and attempts to prioritize one over the other are mythical if not too much simplistic.

Keywords: linguistic relativity; language and thought; extralinguistic thought.

Copyright @ 2019: This is an open-access article distributed under the terms of the Creative Commons Attribution license which permits unrestricted use, distribution, and reproduction in any medium for non-commercial use (NonCommercial, or CC-BY-NC) provided the original author and source are credited.

\section{INDRODUCTION}

According to Bermudez [1] even those who believe that thought can exist without thought had little idea how to study thought without resort to language through which thought is expressed. Bermudez [1] contends that cognitive archeologists are finding evidence of thinking behavior long before even the earliest tenable dates proposed for the emergence of human language. Bermudez [1] further asserts that theoretical discussions of nonlinguistic thought is either inclined toward denying the possibility of a nonlinguistic thought or speculations about vehicles of non-linguistic thought. One very influential philosophical conception about the essence of thought, based on Frege's writings, is based on the belief that the study of thought is only possible via studying the sentences that express them. Theories influenced by this view about the nature of thought will find the notion of thought without language highly problematic.

Davidson [2, 3], cited in Perez [4], believes that those who can communicate with each other by means of a spoken language can think. The main arguments proposed by Davidson are as follow:

- Every propositional attitude (every thought) requires a background of beliefs. This means that although beliefs are not basic in the sense that we cannot reduce all propositional attitudes to beliefs, we can attribute a propositional attitude to an individual just in case we attribute at the same time many beliefs to her. Without beliefs there are no propositional attitudes. Thus, the rest of the argument will be centered on beliefs.

- In order to have a belief it is necessary to have the concept of belief. This is the most disputable premise of the argument. Davidson's argument for it is based upon the most peculiar feature of "thought" according to his view: its rationality. The idea is this: given the fact that every belief entails a number (infinitely many) of other beliefs and other propositional attitudes, and that every belief is capable of being revised in the light of other beliefs, to have a belief is to be prepared to change our beliefs in the light of new information, i.e. we have to be prepared to distinguish what we merely believe from what is objectively true. In brief, to have a belief is to be in a state governed by rationality, and rationality and objective truth go hand in hand; therefore, to have a belief is to have the concept of belief, i.e. the concept of objective truth.

- In order to have the concept of belief one must have language. This is Davidson's weakest 
premise. In fact, he admits he can only prove that the concept of objective (inter-subjective) truth suffices as a basis for beliefs, but not that the only way to have the concept of belief is by having the notion of objective truth, i.e. by triangulating with another speaking person and communicating with each other using a shared language [3] or interpreting each other utterances [2].

- (Conclusion) There are no thoughts without language.

Davies [5] defines ontological priority as the belief that language is ontologicaaly dependent on thought, when thought is not so dependent on language. This means that there cannot be language without thought, but there can be thought without language.

To say that thought enjoys epistemological priority over language is to say that the route to knowledge about language (specifically, about linguistic meaning) goes via knowledge about thought (specifically, about the contents of thought), while knowledge about thought can be had without going via knowledge about language (p. 226).

\section{LINGUISTIC RELATIVITY}

According to Lucy [6] linguistic relativity hypothesis is based on the idea that the particular language we speak influences the way we think about reality. He believes that this hypothesis forms part of the general question of how language has an influence on our thought. Lucy [6] asserts that such potential influences can be classified into three types or levels. At the semiotic level the question is how speaking a particular language may influence thinking. The point is that whether having a code with a symbolic nature (compared to iconic or indexical) transforms thinking. The second type is a structural level which is concerned with the finding an answer to the question that whether speaking two different languages result in different types about reality due to their different morphosyntactic configurations of meaning. This is the level which has been traditionally associated with linguistic relativity. At the functional level it is asked whether employing language in a particular way may influence thinking. This is referred to as functional relativity of thought which believes that speakers who use a language differently have different thinking patterns. According to Marina [7] linguistic relativity is a complicated multilevel and multidimensional issue which is based on the relations between language, thought, experience (reality), and culture. Mariana [7] maintains that relativity believes that every language presents its own picture differently compared to other languages. This would be the result of various handling of the same piece of reality by different languages.

Pinker [8], cited in Slobin [9], refutes SapirWhorf hypothesis altogether can asserts that there is no scientific evidence that languages dramatically shape their speakers' ways o thinking.

Whorf was surely wrong when he said that one's language determines how one conceptualizes reality in general. But he was probably correct in a much weaker sense: one's language does determine how one must conceptualize reality when one has to talk about it $[10,9]$.

Pinker [8], cited in Casasanto [11], further maintains that the fallacy of language equals thought has been brought about by a lack of scientific vigor in the past:

The idea that language shapes thinking seemed plausible when scientists were in the dark about how thinking works, or even how to study it. Now that scientists know how to think about thinking, there is less of a temptation to equate [thinking] with language (p. 65).

Pinker [8], cited in Casasanto [11], refutes both Whorf's argument that "language shapes thought" and Orwell's argument that "we think in language". The argument that he provides against Orwell's position is that:

We have all had the feeling that we know what we want to say but we do not know how to say it, therefore there must be some difference between what we say and what we want to say. Other arguments stress the inadequacy of language as a medium for thought, pointing to problems such as ambiguity, deixis, and coreference, which seem to require extralinguistic resources to resolve. For example, when we read the ambiguous headline "Hershey Bars

Protest" [8], the information we need to decide whether this story discusses an oppressive chocolate manufacturer or some rebellious candy bars does not appear to reside in language, per se (p. 66).

Pinker [8], cited in Casasanto [11], provides the following as the counterargument for Whorf's beliefs:

Two things were wrong with some of Whorf's most notorious claims. To start, many of Whorf's linguistic observations did not stand up to scrutiny by later scholars. Arguably, speakers of Eskimo languages do not use any more words for snow than your average snowboarding enthusiast [12].

Hopi speakers' way of talking about time may not be as different from the SAE speakers' as Whorf made it seem [13]. If there are not actually any relevant differences between languages, then there is no reason to posit differences in the thoughts of their speakers. Furthermore, the project of inferring cognitive 
differences solely from linguistic differences is hopelessly circular. Patterns in language can serve as a source of hypotheses about cognitive differences between members of different language communities, but some sort of extralinguistic data are needed to test these hypotheses: Otherwise, the only evidence that people who talk differently also think differently is that they talk differently! (p. 67).

Carruther and Boucher [14, 15], cited in Slezak [16], maintain that language serve for communication thoughts rather than a vehicle embodying them.

\section{REFERENCES}

1. Bermudez, J. L. (2003). Thinking without words. Oxford University Press.

2. Davidson, C. G. (1975). 14) IF f lag D 0 THEN. Journal of Computational Physics, 17, 8794.

3. Davidson, W. H. (1982). Global strategic management. John Wiley \& Sons Incorporated.

4. Perez, D. I. (2005). Is thought without language possible? Principia, 9:177-191.

5. Davies, M. (1998). Language, thought, and the language of thought: Aunty's own argument revisited. In Carruthers, P., \& Boucher, J. (Eds.), Language and Thought (pp. 226-248). Cambridge University Press.

6. Lucy, J. A. (1997). Linguistic relativity. Annual Review of Anthropology, 26:291-312.

7. Mariana, V. (2008). Linguistic relativity and its theoretical and practical value at the time of globalization. Santalka Filologija Edukologija, 16(2):57-66.

8. Pinker, S. (1994). The language instinct. New York, NY, US: William Morrow \& Co.

9. Slobin, D. I. (2003). Language and thought online: Cognitive consequences of linguistic relativity. In Gentner D., \& Goldin-Meadow, S. (Eds.), Language and mind: Advances in the study of language and thought (pp. 157-192). Cambridge, MA: MIT Press.

10. Pinker, S. (1989). Resolving a learnability paradox in the acquisition of the verb lexicon. Paul H. Brookes Publishing.

11. Casasanto, D. (2008). Who's afraid of the big bad Whorf? Cross-linguistic differences in temporal language and thought. Language Learning, 58(1):63-79.

12. Pullum, G. K. (1991). The great Eskimo vocabulary hoax and other irreverent essays on the study of language. University of Chicago Press.

13. Malotki, E. (1983). Hopi Time. A Linguistic Analysis of the Temporal Concepts in the Hopi Language. Mouton Publishers.

14. Carruthers, P., \& Smith, P. K. (Eds.). (1996). Theories of theories of mind. Cambridge University Press.

15. Carruthers, P., \& Boucher, J. (Eds.). (1998). Language and thought: Interdisciplinary themes. Cambridge University Press.

16. Slezak, P. (2002). Thinking about thinking: Language, thought, and introspection. Language and Communication, 22:353-373. 